\title{
A Novel Synthetic Route for the Preparation of an Amorphous Co/Fe Prussian Blue Coordination Compound with High Electrocatalytic Water Oxidation Activity
}

\author{
Merve Aksoy, ${ }^{\dagger}$ Satya Vijaya Kumar Nune, ${ }^{\dagger}$ and Ferdi Karadas*, ${ }^{\dagger}, \ddagger$ \\ ${ }^{\dagger}$ Department of Chemistry and ${ }^{\ddagger}$ UNAM Institute of Materials Science and Nanotechnology, Bilkent University, 06800 Ankara, \\ Turkey
}

Supporting Information

\begin{abstract}
Co/Fe Prussian Blue coordination networks have recently been investigated for heterogeneous water oxidation catalysis. Despite their robustness and stability in both acidic and neutral media, the relatively low current density obtained is their main drawback as a result of their low surface concentration. A novel synthetic approach was employed using a pentacyanometalate-based metallopolymer for the preparation of amorphous $\mathrm{Co} / \mathrm{Fe}$ coordination polymers to overcome this problem. The surface concentration was improved approximately 7-fold, which also resulted in an increase in the catalytic activity. A current density of $1 \mathrm{~mA} \cdot \mathrm{cm}^{-2}$ was obtained only at $\eta=510 \mathrm{mV}$, while the same current density could be obtained at higher overpotentials $(>600$ $\mathrm{mV}$ ) with conventional Prussian Blue analogues. IR, X-ray photoelectron spectroscopy, and energy-dispersive X-ray spectroscopy studies were performed to investigate the stability of electrodes before and after the electrocatalytic process. The results of this study indicate that the rich and diverse chemistry of pentacyanometalates makes them potential candidates for application in heterogeneous water oxidation catalysis.
\end{abstract}

\section{INTRODUCTION}

Global energy demand is expected to double by 2050, and this level of increase cannot be met using conventional fossil-based fuels such as coal, oil, and natural gas. ${ }^{1}$ This implicates a huge expansion in nuclear energy, which again is nonrenewable and hazardous and generates radioactive waste. There is, therefore, an urgent need to develop alternative methods for energy production that are clean and renewable. ${ }^{2}$ Hydrogen is one of the promising candidates of renewable energy sources because it has high energy content per mass ${ }^{3}$ and produces only water as a product. ${ }^{4}$ One of the main bottlenecks in hydrogen economy is the development of efficient and robust water oxidation catalysts (WOCs)..$^{5-8}$

Even though metal oxides have been the primary focus, ${ }^{9-16}$ significant efforts have also been devoted to exploring nonoxide coordination compounds in the field. ${ }^{17-22}$ Of these, recent advances in the application of $\mathrm{CoN}_{6}$ matrixes as WOCs created opportunity to a wide array of compounds of interest in this field. ${ }^{23-28}$ The investigation of Prussian Blue analogues (PBAs) as WOCs by Galán-Mascarós et al. is one of the benchmark studies showing that non-oxide coordination networks could, in fact, be an alternative to cobalt oxide matrixes given their stability and robustness even in the acidic media. ${ }^{29-31}$ The investigations of similar coordination polymers by the same group in a follow-up study ${ }^{30}$ and a cyanide matrix with $\mathrm{Co}$ and $\mathrm{Pt}$ ions by Yamada et al. for visible-light-driven water oxidation catalysis clearly show that more studies should be performed to engage cyanide chemistry with water oxidation catalysis. ${ }^{32}$ While metal cyanide networks in are the lead with regard to their superior stabilities, easy preparation methods, and competitive catalytic performances compared to cobalt oxides, they lag behind because of their low current densities, which could be attributed to their low number of active Co sites, also called the surface concentration. Because PBAs have surface concentration in the $\mathrm{nmol} \cdot \mathrm{cm}^{-2}$ range, a current density of $1 \mathrm{~mA} \cdot \mathrm{cm}^{-2}$ could only be achieved at higher overpotentials, above $600 \mathrm{mV}$ for conventional PBAs.

The main reason for the relatively low number of active sites in cyanide systems is that most of the Co sites in the crystalline framework are connected to six $\mathrm{N}$ atoms of the cyanide group except the ones on the surface and the atoms inside the vacancies created to provide charge balance. It is, therefore, evident that metal cyanide networks with low or no crystallinity should be prepared to obtain a current density of $1 \mathrm{~mA} \cdot \mathrm{cm}^{-2}$ at much lower overpotentials. Because the conventional synthetic method to obtain PBAs, which involves the reaction of hexacyanometal complexes with transition-metal ions, leads to the formation of highly crystalline compounds, cyanide precursors other than hexacyanometal complexes should be

Received: January 6, 2016

Published: April 13, 2016 
used as precursors to reduce the crystallinity of metal cyanide networks. An important class of cyanide complexes, pentacyanoiron complexes with $\mathrm{N}$-donor ligands, have widely been studied particularly in the 1980s because of their interesting optical and electrochemical properties. ${ }^{33,34}$ They have wellestablished chemistry, straightforward synthetic procedures, and rich chemistry because a pentacyanoiron complex with a $\mathrm{N}$ donor ligand could easily be prepared by reacting the complex $\left[\mathrm{Fe}(\mathrm{CN})_{5} \mathrm{NH}_{3}\right]^{3-}$ with a $\mathrm{N}$-donor ligand such as pyridine derivatives, amino acids, amines, and even polymers with available $\mathrm{N}$ atoms.

Herein, it is aimed to obtain metal cyanide coordination compounds with amorphous behavior using pentacyanoferrate/ poly(4-vinylpyridine) hybrid metallopolymers as precursors. The synthesis and characterization of amorphous cobalt pentacyanoferrate/poly(4-vinylpyridine) hybrid compounds are reported. Electrochemical and electrocatalytic water oxidation studies performed on the aforementioned samples deposited on a F-doped tin oxide (FTO) electrode are also the focus of this study.

\section{EXPERIMENTAL SECTION}

Synthesis. Starting Materials. All of the reagents and solvents were of analytical grade and were received from Sigma-Aldrich and used as such without any further processing. All solutions were prepared with deionized water (resistivity: $18 \mathrm{~m} \Omega \cdot \mathrm{cm}$ ).

$\mathrm{Na}_{3}\left[\mathrm{Fe}^{\prime \prime}(\mathrm{CN})_{5} \mathrm{NH}_{3}\right] \cdot 3 \mathrm{H}_{2} \mathrm{O}$. The compound will be abbreviated as [Fe$\mathrm{NH}_{3}$ ] throughout the manuscript. It was prepared from $\mathrm{Na}_{2}\left[\mathrm{Fe}^{\text {III }}(\mathrm{CN})_{5} \mathrm{NO}\right] \cdot 2 \mathrm{H}_{2} \mathrm{O}$ (sodium nitroferricyanide) according to the procedure reported in the literature. ${ }^{35} \mathrm{~A}$ total of $5 \mathrm{~g}$ of $\mathrm{Na}_{2}\left[\mathrm{Fe}(\mathrm{CN})_{5} \mathrm{NO}\right] \cdot 2 \mathrm{H}_{2} \mathrm{O}$ was dissolved in $20 \mathrm{~mL}$ of water. A total of $1 \mathrm{~g}$ of $\mathrm{NaOH}$ was added to the solution under constant stirring at $10{ }^{\circ} \mathrm{C}$. A $25 \%$ (v/v) $\mathrm{NH}_{4} \mathrm{OH}$ solution was added until saturation, followed by the addition of cold methanol. ${ }^{36}$ The resulting yellow precipitate was aged overnight at $0{ }^{\circ} \mathrm{C}$. The product was recrystallized using a $\mathrm{NH}_{4} \mathrm{OH} / \mathrm{CH}_{3} \mathrm{OH}$ solution. The yield was $50 \%$. Elem anal. Calcd for $\left[\mathrm{Fe}-\mathrm{NH}_{3}\right]$ : C, 18.42; N, 25.78; H, 2.783. Found: C, 18.96; N, 25.34; $\mathrm{H}, 3.001$. An atomic ratio of $1: 3$ for $\mathrm{Fe} / \mathrm{Na}$ was confirmed by energy-dispersive X-ray spectroscopy (EDX). IR $\left(\mathrm{cm}^{-1}\right): 2033(\mathrm{~s})$, 1619 (w), 1260 (Figure S1).

Pentacyanoferrate-Coordinated Poly(4-vinylpyridine), $\mathrm{Na}{ }_{15}(\mathrm{Fe}$ $\left.(\mathrm{CN})_{5}\right)_{5}\left(\mathrm{C}_{7} \mathrm{H}_{7} \mathrm{~N}\right)_{6}\left(\mathrm{H}_{2} \mathrm{O}\right)_{15}$. The compound will be abbreviated as $\left[\mathrm{Fe}(\mathrm{CN})_{5}\right.$-PVP] throughout the manuscript. A synthesis similar to that in the literature was followed. ${ }^{37,38}$ Poly(4-vinylpyridine) (200 $\mathrm{mg}$ ), abbreviated as P4VP throughout the manuscript, was dissolved in $50 \mathrm{~mL}$ of methanol at room temperature. A total of $600 \mathrm{mg}$ of [Fe$\mathrm{NH}_{3}$ ] was added slowly in the solution under constant stirring. After $15 \mathrm{~min}$, the color of the suspension changed from yellow to orange. The reaction was allowed to continue in a covered flask for 3 days. The green precipitate was washed with methanol, followed by centrifugation $(6000 \mathrm{rpm})$, to remove the unlinked pentacyanoammino complex. A total of $250 \mathrm{~mL}$ of cold $\mathrm{Et}_{2} \mathrm{O}$ was added to the green $\mathrm{Fe}(\mathrm{CN})_{5}$-co-P4VP suspension (approximately $50 \mathrm{~mL}$ ) under constant stirring. The brown precipitate was isolated and dried under vacuum overnight at room temperature, resulting in a yellowish-green powder. The yield was $60 \%$. Elem anal. Calcd for $\left[\mathrm{Fe}(\mathrm{CN})_{5}\right.$-PVP]: C, 36.99; N, 19.96; H, 3.336. Found: C, 36.43; N, 18.83; H, 3.387. An atomic ratio of 1:3 for Fe/Na was confirmed by EDX. IR $\left(\mathrm{cm}^{-1}\right): 2041,1600$, and 1417 (Figure S1). The shift observed in UV-vis spectral studies revealed the replacement of the $\mathrm{NH}_{3}$ ligand with P4VP (Figure S2).

Cobalt Hexacyanoferrate, $\mathrm{K}_{0.7} \mathrm{CO}_{1.65}\left[\mathrm{Fe}(\mathrm{CN})_{6}\right] \cdot \mathrm{xH}_{2} \mathrm{O}$. The compound will be abbreviated as $\left[\mathrm{CoFe}(\mathrm{CN})_{6}\right]$ throughout the manuscript. By using the reported drop-by-drop procedure, ${ }^{39} 50 \mathrm{~mL}$ of a 10 $\mathrm{mM}\left[\mathrm{Fe}(\mathrm{CN})_{6}\right]^{4-}$ solution was prepared at room temperature. A total of $50 \mathrm{~mL}$ of a $20 \mathrm{mM} \mathrm{Co}\left(\mathrm{NO}_{3}\right)_{2}$ solution was added dropwise under constant stirring. The resulting bright-green solution was left under stirring for $1 \mathrm{~h}$ at room temperature. A total of $100 \mathrm{~mL}$ of acetone was added, and the suspension was centrifuged at $6000 \mathrm{rpm}$ for $15 \mathrm{~min}$. The precipitate was washed with an acetone/water mixture $(1: 1, \mathrm{v} / \mathrm{v})$. The purification process was repeated three times. The product was collected with the addition of pure acetone and dried in an oven at 35 ${ }^{\circ} \mathrm{C}$ for 1 day. The yield was $73 \%$. IR $\left(\mathrm{cm}^{-1}\right): 2080$. An atomic ratio of 1:1.65 for $\mathrm{Fe} / \mathrm{Co}$ was confirmed by EDX, indicating that the resulting coordination compound is $\left[\mathrm{CoFe}(\mathrm{CN})_{6}\right]$ (Figure S3a).

Cobalt Pentacyanoferrate/Poly(4-vinylpyridine), $\mathrm{Co}_{3}\left[\mathrm{Fe}(\mathrm{CN})_{5}\right]_{2-}$ CO-P4VP. $\mathrm{H}_{2} \mathrm{O}$. The compound will be abbreviated as $\left[\mathrm{CoFe}(\mathrm{CN})_{5_{5}^{-}}\right.$ $\mathrm{PVP}]$ throughout the manuscript. For the drop-by-drop procedure, $50 \mathrm{~mL}$ of a $10 \mathrm{mM}\left[\mathrm{Fe}(\mathrm{CN})_{5}\right]^{3-}-c o-\mathrm{P} 4 \mathrm{VP}$ solution was prepared at room temperature. A total of $50 \mathrm{~mL}$ of a $15 \mathrm{mM} \mathrm{Co}\left(\mathrm{NO}_{3}\right)_{2}$ solution was added dropwise under constant stirring. The resulting dark-green solution was left under stirring for $1 \mathrm{~h}$ at room temperature. A total of $100 \mathrm{~mL}$ of acetone was added, and the suspension was centrifuged at $6000 \mathrm{rpm}$ for $15 \mathrm{~min}$. The precipitate was washed with an acetone/ water mixture $(1: 1, \mathrm{v} / \mathrm{v})$. The purification process was repeated three times. The product was collected with the addition of pure acetone and dried in an oven at $35{ }^{\circ} \mathrm{C}$ for 1 day. The yield was $\sim 55 \%$. IR $\left(\mathrm{cm}^{-1}\right): 2051$ (Figure S1). An atomic ratio of 1:1.38 for Fe/Co was confirmed by EDX with traces of $\mathrm{Na}$, indicating that the resulting coordination compound is $\mathrm{Co}_{1.5}\left[\mathrm{Fe}(\mathrm{CN})_{5} \mathrm{PVP}\right] \cdot x \mathrm{H}_{2} \mathrm{O}$ (Figure S3b).

Cyanoferrate-Modified FTO Electrodes. Cobalt hexacyanoferrate modified and cobalt pentacyanoferrate/poly(4-vinylpyridine) modified FTO electrodes will be abbreviated as $\left[\mathrm{CoFe}(\mathrm{CN})_{6} @ \mathrm{FTO}\right]$ and $\left[\mathrm{CoFe}(\mathrm{CN})_{5}\right.$-PVP@FTO], respectively. A two-step in situ method was used to prepare the electrodes, which includes spin-coating the pentacyanoferrate precursor onto the FTO surface followed by dipping it in a cobalt solution. This method resulted in more stable and robust coatings of the catalyst compared to conventional methods such as drop-casting. Solutions of $0.15 \mathrm{M} \mathrm{Co}\left(\mathrm{NO}_{3}\right)_{2} \cdot 6 \mathrm{H}_{2} \mathrm{O}$ and $0.1 \mathrm{M}$ $\left[\mathrm{Fe}(\mathrm{CN})_{5}-\mathrm{PVP}\right]$ were prepared with Millipore water. A $\left[\mathrm{Fe}(\mathrm{CN})_{5}\right.$ PVP] solution was spin-coated onto FTO electrodes at $1500 \mathrm{rpm}$ for 2 min, resulting in a greenish-yellow translucent layer. Then, the electrode was immersed in a solution of $\mathrm{Co}^{\mathrm{II}}$ for $15 \mathrm{~min}$. This process was repeated twice, and the electrodes were kept in a vacuum desiccator until further use. The electrodes were rinsed with deionized water prior to use. Similar coatings were made onto FTO electrodes (at $1500 \mathrm{rpm}$ for $2 \mathrm{~min}$ ) using $0.2 \mathrm{M} \mathrm{Co}\left(\mathrm{NO}_{3}\right)_{2} \cdot 6 \mathrm{H}_{2} \mathrm{O}$ and $0.1 \mathrm{M}$ $\left[\mathrm{Fe}(\mathrm{CN})_{6}\right]^{4-}$ solutions.

Physical Measurements. Elemental analyses were performed with a Thermo Scientific FLASH 2000 CHNS/O analyzer. IR spectra were measured using a Bruker ALPHA Platinum-ATR spectrometer in the wavenumber range $4000-400 \mathrm{~cm}^{-1}$. UV-vis analysis was performed employing an Agilent Technologies Cary $300 \mathrm{UV}-$ vis spectrophotometer. X-ray diffraction (XRD) patterns were recorded by a Panalytical X'PertPro multipurpose X-ray diffractometer employing $\mathrm{Cu} \mathrm{K} \alpha$ radiation $(\lambda=1.5418 \AA)$. Scanning electron microscopy (SEM) imaging and EDX analysis were carried out using a FEI-Quanta 200 FEG scanning electron microscope operated at $30 \mathrm{kV}$. X-ray photoelectron spectroscopy (XPS) studies were performed using a Thermo Scientific K-Alpha X-ray photoelectron spectrometer system operating with an $\mathrm{Al} \mathrm{K} \alpha$ microfocused monochromator source $(h \nu$, $1486.6 \mathrm{eV}$; spot size, $400 \mathrm{~mm}$; pass energy, $30 \mathrm{eV}$ ) along with a flood gun for charge neutralization. Origin Pro 8.5 was used to plot and analyze all of the graphs.

Electrochemical Measurements. Electrochemical experiments were performed at room temperature using a Gamry Instruments Interface 1000 potentiostat/galvanostat. A conventional three-electrode electrochemical cell was used, with $\mathrm{Ag} / \mathrm{AgCl}(3.5 \mathrm{M} \mathrm{KCl})$ as the reference electrode, Pt wire as the counter electrode, and FTO as the working electrode $\left(1 \times 2 \mathrm{~cm} ; 2 \mathrm{~mm}\right.$ slides with $7 \Omega \cdot \mathrm{sq}^{-1}$ surface resistivity and $\sim 80 \%$ transmittance). Before preparation of the electrode, the FTO slides were cleaned prior to use. Briefly, the FTO slides were washed by sonication for $15 \mathrm{~min}$ in a basic soapy solution, deionized water, and isopropanol, followed by annealing at $400{ }^{\circ} \mathrm{C}$ for $30 \mathrm{~min}$. Buffer solutions were prepared using $\mathrm{K}_{2} \mathrm{HPO}_{4}$ and $\mathrm{KH}_{2} \mathrm{PO}_{4}(\mathrm{KPi})$ and adjusted by adding $\mathrm{H}_{3} \mathrm{PO}_{4}$ or $\mathrm{KOH}$ to the desired $\mathrm{pH}$. Cyclic voltammograms were recorded in $50 \mathrm{mM} \mathrm{KPi}(\mathrm{pH} 7)$ containing $1 \mathrm{M}$ $\mathrm{KNO}_{3}$ as electrolytes between -0.4 and $+1.5 \mathrm{~V}$ (vs $\mathrm{Ag} / \mathrm{AgCl}$ ). All 
experiments were carried out under a $\mathrm{N}_{2}$ atmosphere. All three electrodes were dipped in the buffer solution, and the solution was bubbled with $\mathrm{N}_{2}$ gas for 15 min to remove the dissolved $\mathrm{O}_{2}$ gas. The system was closed and remained closed throughout the measurement.

Bulk Water Electrolysis and Tafel Analysis. Bulk water electrolysis was performed with a two-compartment cell with a glass frit separation. Counter and reference electrodes were placed in their respective compartments. The electrolysis experiments were carried out in a $\mathrm{KPi}$ buffer ( $\mathrm{pH}$ 7) solution containing $1 \mathrm{M} \mathrm{KNO}_{3}$ as the supporting electrolyte. Tafel data were collected in the same conditions at different applied potentials using a steady current density of an equilibrium time of $600 \mathrm{~s}$. Oxygen evolution was determined with a YSI 5100 dissolved oxygen sensing instrument equipped with a dissolved oxygen field probe inserted into the anodic compartment. A buffer solution of $130 \mathrm{~mL}$ was used for the electrolysis experiments. The $\mathrm{O}_{2}$ content is recorded at STP conditions, in units of $\mathrm{mg} \cdot \mathrm{L}^{-1}$ and later converted to $\mu$ moles of $\mathrm{O}_{2}$. EDX analysis was then performed on the electrodes to determine the atomic ratio of metal ( $\mathrm{Fe} / \mathrm{Co}$ ) after bulk water electrolysis (Figure S4).

\section{RESULTS AND DISCUSSION}

Synthesis and Characterization. The metallopolymer, pentacyanoferrate/poly(4-vinylpyridine) $\left[\mathrm{Fe}(\mathrm{CN})_{5}\right.$-PVP], was prepared by adopting a similar synthetic approach reported previously $^{37}$ that includes the mixing of P4VP with an excess amount of $\left[\mathrm{Fe}(\mathrm{CN})_{5} \mathrm{NH}_{3}\right]^{3-}$ in methanol. IR studies performed on the compound reveal strong bands at 2041, 1600 , and $1417 \mathrm{~cm}^{-1}$, corresponding to the vibrational modes $\nu(\mathrm{CN}), \nu\left(\mathrm{CN}_{\text {ring }}\right)$, and $\nu\left(\mathrm{CC}_{\text {ring }}\right)$, respectively (Figure $\left.\mathrm{S} 1\right)$. The $\nu\left(\mathrm{CN}_{\text {ring }}\right)$ band at $1595 \mathrm{~cm}^{-1}$ of pure P4VP shifted to 1600 $\mathrm{cm}^{-1}$ for $\left[\mathrm{Fe}(\mathrm{CN})_{5}\right]{ }^{3-}-\mathrm{co}-\mathrm{P} 4 \mathrm{VP} .{ }^{38,40,41}$ The same trend was also noted for the $\nu\left(\mathrm{CC}_{\text {ring }}\right)$ band at $1413 \mathrm{~cm}^{-1}$, which shifted to $1417 \mathrm{~cm}^{-1} \cdot 38,40-42$ The slight shift of the cyanide stretch to higher frequencies compared to the precursor $\left(2031 \mathrm{~cm}^{-1}\right.$ for $\left.\left[\mathrm{Fe}-\mathrm{NH}_{3}\right]\right)$ indicates successful substitution of the amino ligands with the P4VP group without effecting the oxidation state of the $\mathrm{Fe}$ centers. ${ }^{38}$ Similarly, the shift to lower wavelengths observed in the absorbance band in UV-vis spectra also supports the formation of a metal polymer composite (Figure S2). ${ }^{37,38}$ Moreover, the high solubility of $\left[\mathrm{Fe}(\mathrm{CN})_{5}-\mathrm{PVP}\right]$ in water in contrast to P4VP suggests the formation of a charged polymeric species. The metal content in the sample was confirmed by EDX with an atomic ratio of 3:1 $(\mathrm{Na} / \mathrm{Fe})$, which also confirms that there is no change in the oxidation state of Fe. A molecular formula of $\mathrm{Na}_{15}(\mathrm{Fe}$ $\left.(\mathrm{CN})_{5}\right)_{5}\left(\mathrm{C}_{7} \mathrm{H}_{7} \mathrm{~N}\right)_{6}\left(\mathrm{H}_{2} \mathrm{O}\right)_{15}$ was approximated based on the atomic ratio of the metals obtained from the EDX technique and weight percentages of $\mathrm{C}, \mathrm{H}$, and $\mathrm{N}$ atoms obtained from CHN elemental analysis, which reveals that approximately $80 \%$ of the pyridine groups of $\mathrm{P} 4 \mathrm{VP}$ are connected to the pentacyanoiron complex. A $\mathrm{Co} / \mathrm{Fe}$ coordination polymer, $\left[\mathrm{CoFe}(\mathrm{CN})_{5}-\mathrm{PVP}\right]$, was obtained by reacting the metallopolymer, $\left[\mathrm{FeCN}_{5}-\mathrm{PVP}\right]$, with a $\mathrm{Co}^{2+}$ solution. Figure 1 shows the proposed structure of the amorphous compound.

In situ preparation of the metallopolymer on the FTO electrode via a two-step spin-coating method was used to improve the binding of the sample to the substrate. IR studies together with XPS and EDX studies confirm that the samples prepared on the FTO electrode by an in situ preparation method and the bulk samples are identical (Figure S5). A shift in the cyanide stretch to higher frequencies was observed, which can be attributed to the binding of a terminal $\mathrm{N}$ atom of the cyanide group to a Co ion. EDX of the resulting complex showed an $\mathrm{Fe} / \mathrm{Co}$ ratio in good agreement with that of the bulk complex.

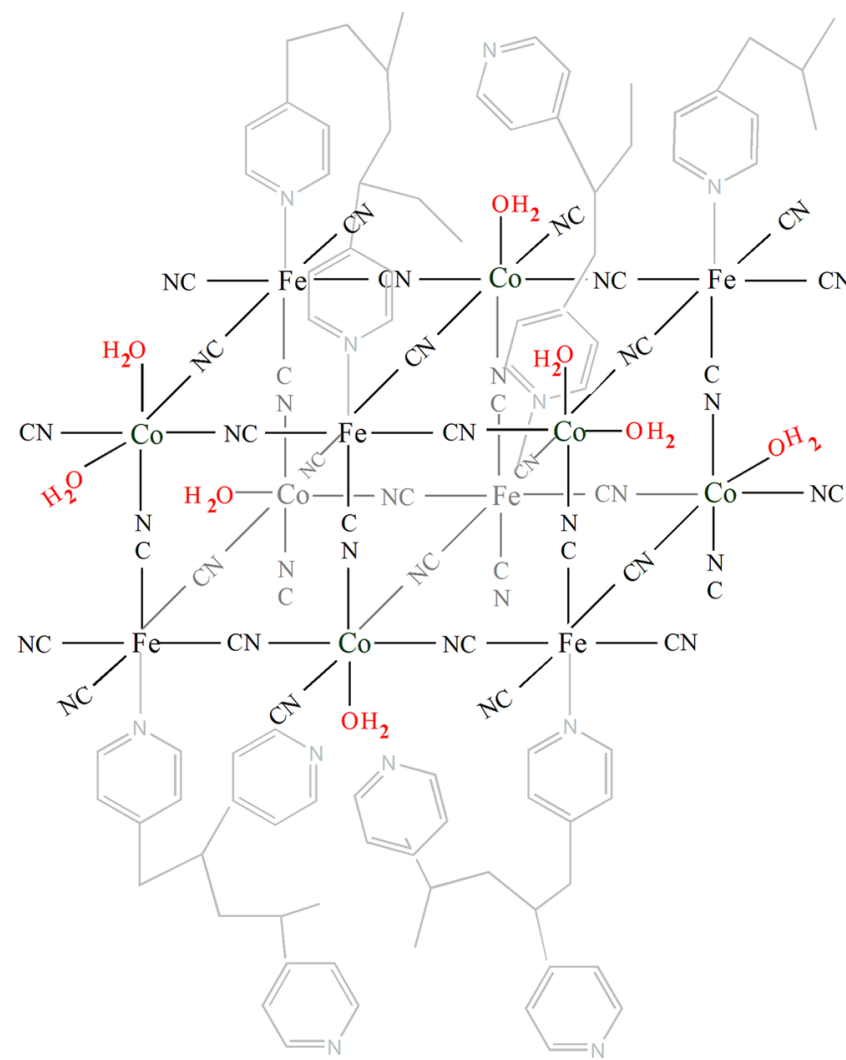

Figure 1. Proposed structure for the cobalt pentacyanoferrate/poly(4vinylpyridine) catalyst $\left[\mathrm{CoFeCN}_{5}-\mathrm{PVP}\right]$.

Electrochemistry. Electrochemical and electrocatalytic studies were performed at $\mathrm{pH} 7$ using a standard phosphate buffer in the presence of $1 \mathrm{M} \mathrm{KNO}_{3}$. Cyclic voltammetry of $\left[\mathrm{CoFe}(\mathrm{CN})_{5}\right.$-PVP] deposited on the FTO electrode (denoted as $\left[\mathrm{CoFe}(\mathrm{CN})_{5}\right.$-PVP@FTO]) was recorded in the -0.4 to $-1.8 \mathrm{~V}$ range with respect to a $\mathrm{Ag} / \mathrm{AgCl}$ reference electrode (Figure 2). It exhibits two main features: (i) a quasi-reversible redox couple with an oxidation peak at $0.46 \mathrm{~V}$ and a reduction peak at $0.26 \mathrm{~V}$ versus the $\mathrm{Ag} / \mathrm{AgCl}$ reference electrode $\left(E_{1 / 2}=\right.$ $\left.0.36 \mathrm{~V} ; E_{\mathrm{c}}-E_{\mathrm{a}}=200 \mathrm{mV}\right)$, which is attributed to the $\mathrm{Co}^{2+} /$ $\mathrm{Co}^{3+}$ redox couple; (ii) an irreversible peak that corresponds to the catalytic water oxidation process. A similar study was also performed with the $\left[\mathrm{CoFe}(\mathrm{CN})_{6} @ \mathrm{FTO}\right]$ electrode (Figure S6). A slight increase in the peak-to-peak separation of the $\mathrm{Co}^{2+} / \mathrm{Co}^{3+}$ redox couple was observed with increasing scan rate due to uncompensated solution resistance $(3.8 \Omega)$, which was obtained from the slope of the linear relationship between the peak-to-peak separation and peak current (Figure S7). From the slope of the linear peak current versus the scan rate plot, the surface concentration of Co sites in [ $\mathrm{CoFe}(\mathrm{CN})_{5}$-PVP@FTO] was calculated as $13.8 \mathrm{nmol} \cdot \mathrm{cm}^{-2}$, while it is $2 \mathrm{nmol} \cdot \mathrm{cm}^{-2}$ for the [CoFe(CN) $\left.{ }_{6} @ \mathrm{FTO}\right]$ electrode (Figures S8 and S9). The dramatic increase in the number of active Co sites with respect to cobalt hexacyanoferrate can be attributed to the limiting effect of the polymeric moiety on the dimensionality of the network. The polymeric group serves not only as a capping ligand by binding to each $\mathrm{Fe}$ center but also as a surfactant because of its chain structure. The size of the cyanide network is confined to $\sim 5 \AA$, which is the length of a $\mathrm{Fe}-\mathrm{CN}-\mathrm{Co}$ binding mode, in at least one dimension because all of the pentacyanoiron groups are connected to the polymeric chain, 


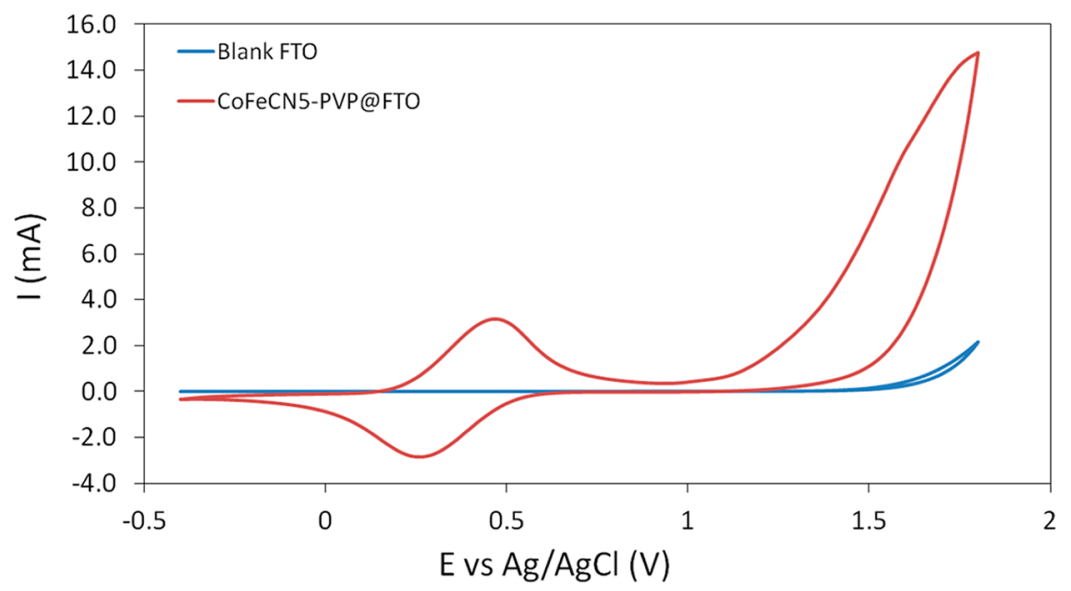

Figure 2. Cyclic voltammogram of the $\left[\mathrm{CoFe}(\mathrm{CN})_{5}-\mathrm{PVP} @ \mathrm{FTO}\right]$ electrode recorded in a $50 \mathrm{mM} \mathrm{KPi}$ electrolyte at pH 7.0 (red line) with a $25 \mathrm{mV}$. $\mathrm{s}^{-1}$ sweep rate. Electrochemical response of a blank FTO electrode (blue line).

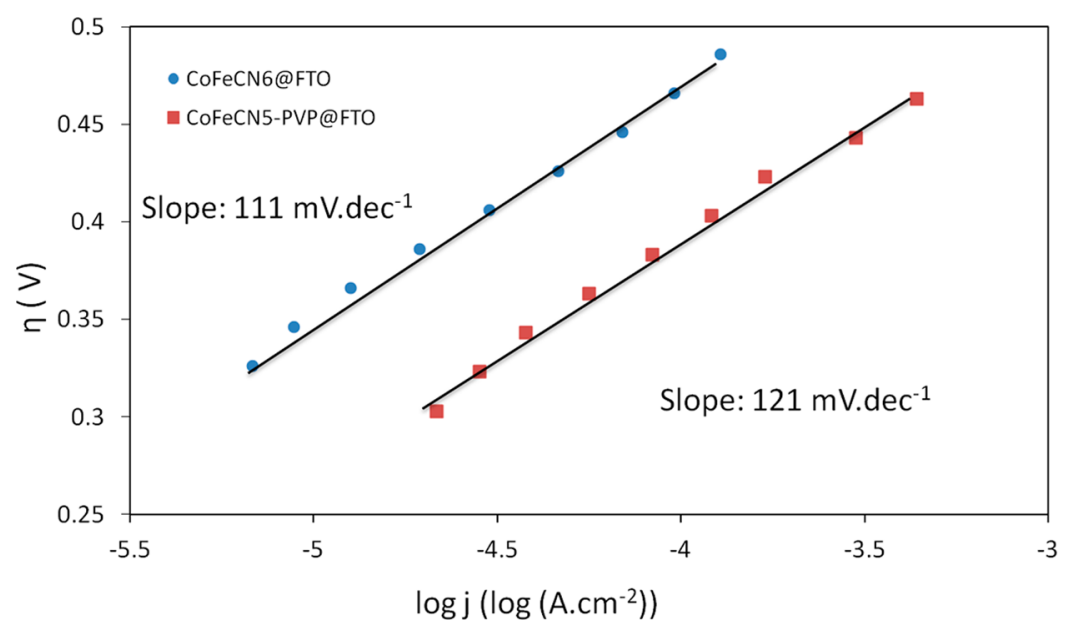

Figure 3. Tafel plots for the $\left[\mathrm{CoFe}(\mathrm{CN})_{6} @ \mathrm{FTO}\right]$ (blue circles) and [ $\mathrm{CoFe}(\mathrm{CN})_{5}$-PVP@FTO] (red squares) electrodes from 0.9 to $1.1 \mathrm{~V}$ versus $\mathrm{Ag} / \mathrm{AgCl}$ electrode recorded in a $50 \mathrm{mM} \mathrm{KPi}$ electrolyte at $\mathrm{pH} 7.0$.

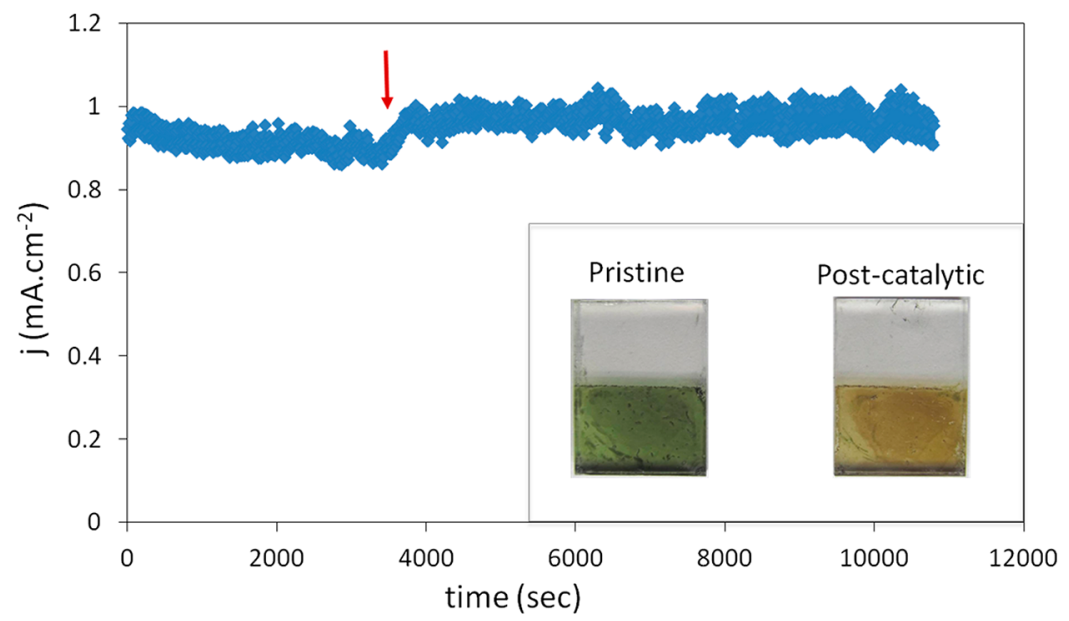

Figure 4. Chronoamperometry measurement of the $\left[\mathrm{CoFe}(\mathrm{CN})_{5}\right.$-PVP@FTO] electrode at $1.2 \mathrm{~V}$ versus $\mathrm{Ag} / \mathrm{AgCl}$ in a $\mathrm{KPi}$ buffer at $\mathrm{pH} 7 . \mathrm{The}$ red arrow indicates the mechanical removal of bubbles. The inset shows the images of the electrodes before and after the catalytic process.

leading to approximately a 7-fold increase in the number of active Co sites.

For evaluation of the catalytic activities of modified electrodes, chronoamperometric measurements were performed to measure the current densities at different over- potentials (Figure 3). The current densities obtained by the $\left[\mathrm{CoFe}(\mathrm{CN})_{6} @ \mathrm{FTO}\right]$ electrode are in good accordance with those in the previous study. ${ }^{29}$ A Tafel slope $\left(111 \mathrm{mV} \cdot \mathrm{dec}^{-1}\right)$ higher than that reported by Galán-Mascarós et al. $(88 \mathrm{mV}$. $\mathrm{dec}^{-1}$ ) was observed because of the use of different deposition 


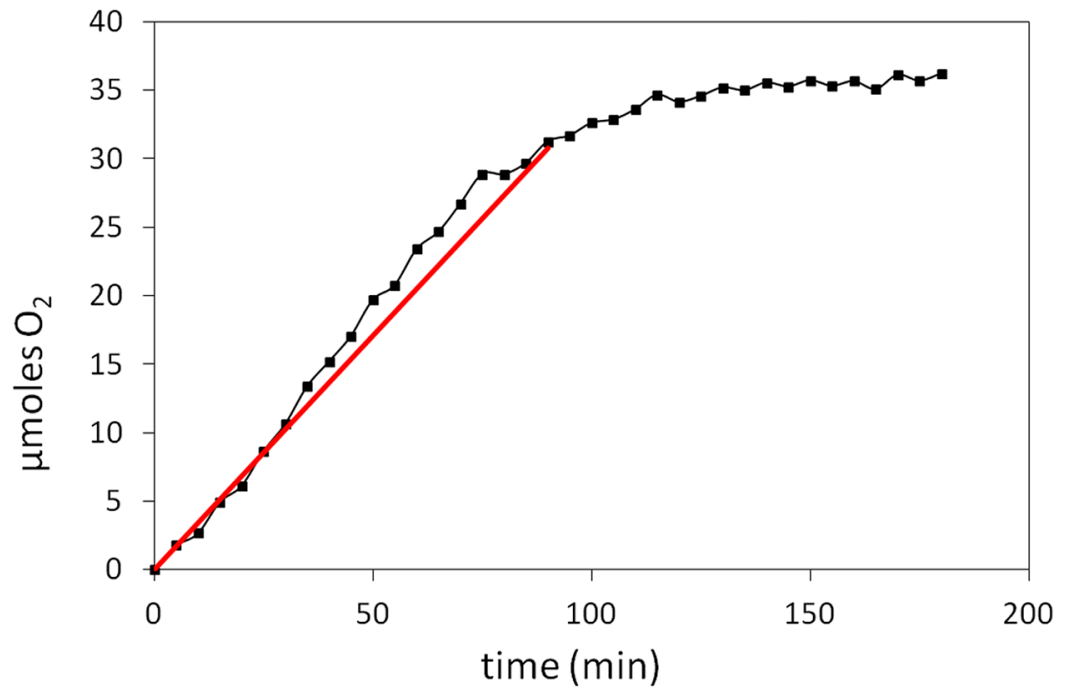

Figure 5. Faradaic efficiency of $\left[\mathrm{Fe}(\mathrm{CN})_{5}-\mathrm{PVP} @ \mathrm{FTO}\right]$ measured by an oxygen-sensor system. Bulk electrolysis was performed at $1.2 \mathrm{~V}$ versus Ag/ $\mathrm{AgCl}$ in a gastight electrochemical cell. The amount of dissolved $\mathrm{O}_{2}$ molecules detected during bulk electrolysis and the theoretical amount of evolved $\mathrm{O}_{2}$ assuming a Faradaic efficiency of $100 \%$ are represented by the black and red lines, respectively.

techniques resulting in a higher amount of catalyst loading. A linear relationship between $\log j$ and the overpotential was obtained in an overpotential range of $300-500 \mathrm{mV}$ with respect to the $\mathrm{Ag} / \mathrm{AgCl}$ reference electrode. A deviation from linearity at higher overpotentials is observed as a result of the formation of oxygen bubbles, which limits mass transport on the electrode surface (Figure S10). Furthermore, a catalytic onset potential of $360 \mathrm{mV}$ is required to produce a current density of $55 \mu \mathrm{A} \cdot \mathrm{cm}^{-2}$, which is in the range of those obtained for other Co-based catalysts (for $\mathrm{Co} / \mathrm{Pi}, \eta=280 \mathrm{mV} ; \eta=310 \mathrm{mV}$ for $\mathrm{Co}\left(\mathrm{PO}_{3}\right)_{2}, \eta$ $=434 \mathrm{mV}$ for $\mathrm{Co}_{3} \mathrm{O}_{4}$, and $\eta=310 \mathrm{mV}$ for CoNCN). Although [CoFe(CN) $)_{5}$-PVP@FTO] exhibits a higher Tafel slope than $\left[\mathrm{CoFe}(\mathrm{CN})_{6} @ \mathrm{FTO}\right]$, a significant improvement in the current densities was observed. A current density of $1 \mathrm{~mA}$. $\mathrm{cm}^{-2}$ could be achieved at $\eta=510 \mathrm{mV}$ for $\left[\mathrm{CoFe}(\mathrm{CN})_{5}\right.$-PVP@ FTO], while the same current density could be obtained above $\eta>600 \mathrm{mV}$ for $\left[\mathrm{CoFe}(\mathrm{CN})_{6} @ \mathrm{FTO}\right]$, mainly as a result of the difference in the number of active Co sites. To check the longterm stability of the catalyst, bulk electrolysis was performed with both $\left[\mathrm{CoFe}(\mathrm{CN})_{5}\right.$-PVP@FTO] (Figure S11) and [CoFe$\left.(\mathrm{CN})_{6} @ \mathrm{FTO}\right]$ (Figure $\mathrm{S} 12$ ) over 2 days at $1.2 \mathrm{~V}$ versus $\mathrm{Ag} /$ $\mathrm{AgCl}$, with regular intervals leaving the electrodes in the electrolyte solution. Similar behavior was observed for both of the samples, where a gradual decrease in the current density initially is observed, followed by a consistent stable current density at each step. The initial decrease could be attributed to the leaching of poorly attached particles from the FTO electrode.

A turnover frequency (TOF) of $2.6 \times 10^{-3} \mathrm{~s}^{-1}$ could be achieved at overpotentials of 262 and $284 \mathrm{mV}$, respectively, for [CoFe $\left.(\mathrm{CN})_{6} @ \mathrm{FTO}\right]$ and [CoFe $(\mathrm{CN})_{5}$-PVP@FTO] (Figure S13). The similarity in the $\log$ TOF versus $\eta$ plots indicates that active Co sites have similar coordination spheres, as expected. The quantity of $\mathrm{O}_{2}$ produced during bulk electrolysis of modified FTO electrodes at a constant potential of $1.2 \mathrm{~V}$ was also monitored for $3 \mathrm{~h}$. A stable current density of $\sim 1 \mathrm{~mA} \cdot \mathrm{cm}^{-2}$ was obtained, which suggests the stability of the electrodes during electrolysis over $3 \mathrm{~h}$ (Figure 4). The quantity of dissolved $\mathrm{O}_{2}$ measured by an oxygen-sensing instrument reached saturation after $2 \mathrm{~h}$. A similar behavior was also observed with the $\left[\mathrm{CoFe}(\mathrm{CN})_{6} @ \mathrm{FTO}\right]$ electrode with a relatively lower current density $\left(450 \mu \mathrm{A} \cdot \mathrm{cm}^{-2}\right.$; Figure $\left.\mathrm{S} 14\right)$, which resulted in a longer time (around two and half hours) to reach saturation compared to that of $\left[\mathrm{CoFe}(\mathrm{CN})_{5}\right.$-PVP@FTO (Figure S15). A theoretical fit that yields the quantity of oxygen calculated using Faraday's law for a $4 \mathrm{e}^{-}$process matches the experimental slope for oxygen evolution, suggesting that the origin of the increase in the current is water oxidation (Figure 5).

Characterization of Electrodes. Characterization studies were also performed for electrodes after bulk electrolysis at 1.2 $\mathrm{V}$ versus $\mathrm{Ag} / \mathrm{AgCl}$. SEM imaging was performed on the $\left[\mathrm{CoFe}(\mathrm{CN})_{5}\right.$-PVP@FTO] electrodes to investigate the morphology of the coating (Figure 6). The image suggests that the

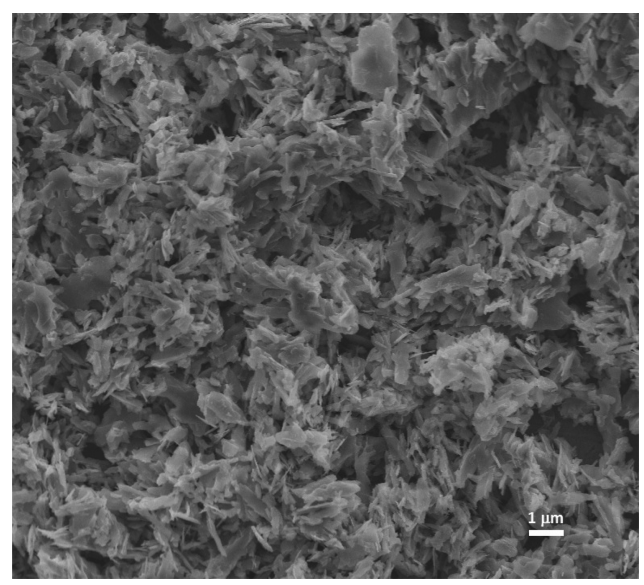

Figure 6. SEM image of the $\left[\mathrm{CoFe}(\mathrm{CN})_{5}-\mathrm{PVP} @ \mathrm{FTO}\right]$ electrode.

coating is consistent with no long-term orderliness, which also explains the amorphous nature of the catalyst (XRD pattern in Figures S16 and S17). The coating exhibits submicron-sized catalyst particles distributed uniformly all over the electrode surface.

A color change from green to brown as a result of partial oxidation of Co sites was observed during electrolysis. IR and XPS studies were performed to investigate the behavior of 

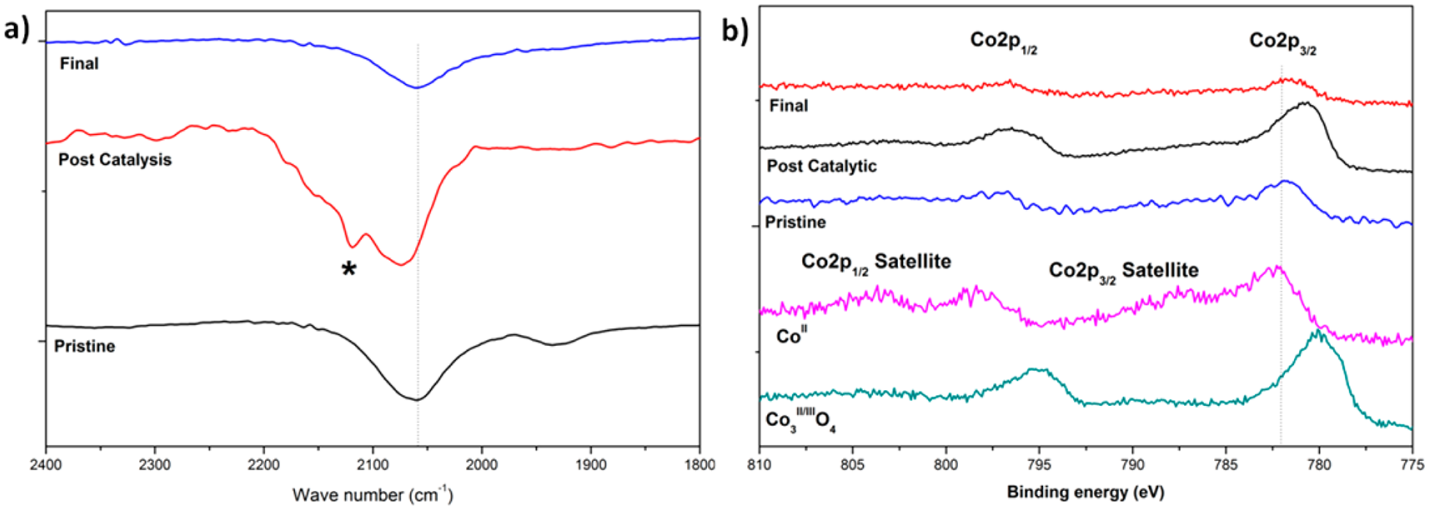

Figure 7. (a) IR spectra of the $\left[\mathrm{CoFe}(\mathrm{CN})_{5}-\mathrm{PVP} @ \mathrm{FTO}\right]$ electrode before (pristine), after $3 \mathrm{~h}$ of bulk electrolysis (postcatalytic), and after a reduction potential of $-200 \mathrm{mV}$ is applied for $30 \mathrm{~min}$ to the postcatalytic electrode (final) in a KPi buffer solution at $\mathrm{pH}$ 7. The peak represented with an asterisk is attributed to the oxidized $\mathrm{Fe}^{\mathrm{II}}-\mathrm{CN}-\mathrm{Co}^{\mathrm{III}}$ binding mode. (b) XPS spectra of the Co $2 \mathrm{p}$ region of the surface of the pristine, postcatalytic, and final electrodes. The spectra for $\mathrm{Co}_{3} \mathrm{O}_{4}$ and $\mathrm{Co}\left(\mathrm{NO}_{3}\right)_{2}$ were also depicted as references.

partial oxidation as well as the stabilities of the electrodes. IR studies performed on the catalyst scraped from the electrode after electrolysis revealed an additional stretch corresponding to $\mathrm{Fe}^{\mathrm{II}}-\mathrm{CN}-\mathrm{Co}^{\mathrm{III}}$ at $2116 \mathrm{~cm}^{-1}$ as a result of partial oxidation of Co sites (Figure 7a). The presence of the intense asymmetric band at $2059 \mathrm{~cm}^{-1}$ in both the original and postcatalytic samples suggests that the oxidation of Co sites is partial. XPS analysis was performed to further study the oxidation state of the Co sites in the original and postcatalytic electrodes (Figure $7 \mathrm{~b})$. The Co $2 \mathrm{p}_{3 / 2}$ line at $781.88 \mathrm{eV}$ of the original electrode is observed to be in close accordance with that of $\mathrm{Co}^{\mathrm{II}}$ salt $(782.28 \mathrm{eV})$. Additionally, a strong satellite band associated with the Co $2 \mathrm{p}_{3 / 2}$ line at $4-8 \mathrm{eV}$ above the principle band was observed. Likewise, the Co $2 \mathrm{p}_{1 / 2}$ line positioned at $796.68 \mathrm{eV}$ in the pristine sample, slightly chemically shifted from the line corresponding to Co $2 \mathrm{p}_{1 / 2}$ in the $\mathrm{Co}^{\mathrm{II}}$ salt $(798.38 \mathrm{eV})$, is readily identifiable. An additional satellite associated with the Co $2 p_{1 / 2}$ line at 5-6 eV above the principle line was observed. Each of the principle lines exhibits strong bands with scalable full width at half-maxima (fwhm; $>3.5 \mathrm{eV}$ ) suitable for identification. Satellite lines associated with Co $2 \mathrm{p}_{3 / 2}$ and Co $2 p_{3 / 2}$ were, however, broad and, hence, not suitable for identification purposes. In the postcatalytic sample, the Co $2 p_{3 / 2}$ and Co $2 p_{1 / 2}$ lines were observed at 780.58 and 796.48 $\mathrm{eV}$, respectively, which are slightly lower than the binding energies observed for the original sample. Both of the lines exhibit strong bands with a scalable fwhm $(>4 \mathrm{eV})$ and, hence, suitable for identification. The Co $2 \mathrm{p}$ lines for $\mathrm{Co}^{\mathrm{II}}$ and $\mathrm{Co}^{\mathrm{III}}$ generally fall very close or may even overlap and, thus, are generally difficult to differentiate. Earlier studies, however, focused on differentiating $\mathrm{Co}^{\mathrm{II}}$ from $\mathrm{Co}^{\mathrm{III}}$ by observing the satellite bands of the Co $2 \mathrm{p}$ lines; high-spin $\mathrm{Co}^{\mathrm{II}}$ ions have intense or scalable satellite bands, whereas low-spin $\mathrm{Co}^{\mathrm{III}}$ ions have very weak or missing satellite bands. In the postcatalytic sample, very weak to almost negligible satellite bands were observed, indicating that the sample most likely is low-spin $\mathrm{Co}^{\mathrm{III}}$. Therefore, it can be safely concluded that the top layer of the electrode exhibits some degree of oxidation in the postcatalytic sample considering the XPS and IR results.

XPS and IR studies were also performed on the postcatalytic electrodes that were treated with a reduction potential of -200 $\mathrm{mV}$ to test the reversibility of the catalytic cycle. It was observed that the color of the samples turned back to green, which is the color of the original sample. Moreover, a shoulder in the IR spectrum and peaks that correspond to $\mathrm{Co}^{\mathrm{III}}$ ions in XPS disappeared after treatment with the reduction potential. Both IR and XPS spectra are identical with those of the original electrodes. It is, therefore, evident that the catalyst retains its structure during the catalytic process and that oxidation of Co sites is a reversible process. XPS of the $\mathrm{O} 1 \mathrm{~s}$ line (Figure S18) was also observed to investigate the stability of the electrodes. Spectra of both the original and postcatalytic samples exhibit peaks that are attributed to the surface-adsorbed oxygen species. No persistent $\mathrm{O} 1 \mathrm{~s}$ bands are found at binding energies lower than $530 \mathrm{eV}$ that correspond to lattice oxygen species in either of the samples, confirming the absence of any oxidebased species before and after catalysis. Decomposition of cyanide-based clusters to form any Co-based oxides was, thus, ruled out based on comparative XPS studies performed on electrodes and the reference $\mathrm{Co}_{3} \mathrm{O}_{4}$ compound.

\section{CONCLUSIONS}

Several non-oxide coordination networks including $\mathrm{Co} / \mathrm{Fe}$ PBAs have recently been investigated for their electrocatalytic and photocatalytic water oxidation performances. Extended networks with $\left\{\mathrm{CoN}_{6}\right\}$ moieties have progressed in the field thanks to the higher TOFs obtained by Co sites surrounded with $\mathrm{N}$ atoms compared to cobalt oxide systems and their robustness and stabilities in both acidic and neutral media. Non-oxide cobalt systems, however, exhibit low current densities as a result of their low surface concentrations. The synthetic method reported herein aimed to improve the number of active Co sites while retaining the chemical nature of individual Co sites (Co atoms surrounded with terminal $\mathrm{N}$ atoms of bridging cyanide groups) in $\mathrm{Co}-\mathrm{Fe}$ Prussian Blue coordination compounds.

Metallopolymers with pentacyanoiron complexes can be ideal candidates as precursors for amorphous coordination compounds with promising electrocatalytic activities. A metallopolymer with dangling cyanide groups serves as a suitable medium not only to obtain $\left\{\mathrm{CoN}_{6}\right\}$ moieties but also to avoid long-range ordering of metal cyanometalate clusters because of the presence of polymeric chains, which results in an improvement in the number of active Co sites.

Comparable TOFs of $\left[\mathrm{CoFe}(\mathrm{CN})_{6} @ \mathrm{FTO}\right]$ and $[\mathrm{CoFe}-$ $(\mathrm{CN})_{5}$-PVP@FTO] electrodes (a TOF value of $2.6 \times 10^{-3} \mathrm{~s}^{-1}$ could be achieved at overpotentials of 262 and $284 \mathrm{mV}$, respectively, for $\left[\mathrm{CoFe}(\mathrm{CN})_{6} @ \mathrm{FTO}\right]$ and $\left[\mathrm{CoFe}(\mathrm{CN})_{5}-\mathrm{PVP} @\right.$ 
FTO]) are mainly a result of the same type of network structural motif including the $\mathrm{Fe}-\mathrm{CN}-\mathrm{Co}$ type of binding groups, thus similar coordination spheres for active Co sites. A current density of $1 \mathrm{~mA} \cdot \mathrm{cm}^{-2}$ was obtained at much lower overpotentials $(\eta=510 \mathrm{mV})$ with a $\mathrm{CoFe}(\mathrm{CN})_{5}$-PVP-modified FTO electrode as expected mainly as a result of approximately a 7 -fold increase in the number of active Co sites with respect to a conventional cobalt hexacyanoferrate system.

Two disciplines of chemistry, pentacyanometal complexes and water oxidation, have been engaged for the first time. Because pentacyanometal complexes have well-established chemistry, straightforward synthetic procedures, and rich chemistry due to the diversity of $\mathrm{N}$-donor ligands, the strategy outlined in this project will also be used to introduce a series of robust and efficient catalysts to the field of water oxidation. Furthermore, the effect of the surface area on the availability of active metal sites and the activity of the catalyst needs more emphasis.

\section{ASSOCIATED CONTENT}

\section{S Supporting Information}

The Supporting Information is available free of charge on the ACS Publications website at DOI: 10.1021/acs.inorgchem.6b00032.

IR spectra, UV-vis spectra in solution, EDX spectra, cyclic voltammograms, Tafel plots, TOF plots, XRD patterns, and XPS spectra (PDF)

\section{AUTHOR INFORMATION}

\section{Corresponding Author}

*E-mail: karadas@fen.bilkent.edu.tr.

Notes

The authors declare no competing financial interest.

\section{ACKNOWLEDGMENTS}

The authors thank the Science and Technology Council of Turkey, TUBITAK (Project 114Z473), for financial support.

\section{REFERENCES}

(1) Hoffert, M. I.; Caldeira, K.; Jain, A. K.; Haites, E. F.; Harvey, L. D.; Potter, S. D.; Schlesinger, M. E.; Schneider, S. H.; Watts, T. M. L.; Wigley, T. M. L.; Wuebbles, D. J. Nature 1998, 395, 881-884.

(2) Lewis, N. S.; Nocera, D. G. Proc. Natl. Acad. Sci. U. S. A. 2006, 103, 15729-15735.

(3) Jena, P. J. Phys. Chem. Lett. 2011, 2, 206-211.

(4) Durbin, D. J.; Malardier-Jugroot, C. Int. J. Hydrogen Energy 2013, 38, 14595-14617.

(5) Barber, J. Chem. Soc. Rev. 2009, 38, 185-196.

(6) Sartorel, A.; Carraro, M.; Toma, F. M.; Prato, M.; Bonchio, M. Energy Environ. Sci. 2012, 5, 5592-5603.

(7) Shin, S.-M.; Jung, J.-Y.; Park, M.-J.; Song, J.-W.; Lee, J.-H. J. Power Sources 2015, 279, 151-156.

(8) Blankenship, R. E.; Tiede, D. M.; Barber, J.; Brudvig, G. W.; Fleming, G.; Ghirardi, M.; Gunner, M. R.; Junge, W.; Kramer, D. M.; Melis, A.; Moore, T. A.; Moser, C. C.; Nocera, D. G.; Nozik, A. J.; Ort, D. R.; Parson, W. W.; Prince, R. C.; Sayre, R. T. Science 2011, 332, 805-809.

(9) Harriman, A.; Pickering, I. J.; Thomas, J. M.; Christensen, P. A. J. Chem. Soc., Faraday Trans. 1 1988, 84, 2795-2806.

(10) Risch, M.; Grimaud, A.; May, K. J.; Stoerzinger, K. A.; Chen, T. J.; Mansour, A. N.; Shao-Horn, Y. J. Phys. Chem. C 2013, 117, 86288635.

(11) Frey, C. E.; Wiechen, M.; Kurz, P. Dalton Trans. 2014, 43, $4370-4379$.
(12) Li, W.; Sheehan, S. W.; He, D.; He, Y.; Yao, X.; Grimm, R. L.; Brudvig, G. W.; Wang, D. Angew. Chem., Int. Ed. 2015, 54, 1142811432.

(13) Nocera, D. G. Acc. Chem. Res. 2012, 45, 767-776.

(14) Smith, R. D. L.; Prévot, M. S.; Fagan, R. D.; Zhang, Z.; Sedach, P. A.; Siu, M. K. J.; Trudel, S.; Berlinguette, C. P. Science 2013, 340, $60-63$.

(15) Wasylenko, D. J.; Palmer, R. D.; Berlinguette, C. P. Chem. Commun. 2013, 49, 218-227.

(16) Smith, R. D. L.; Prévot, M. S.; Fagan, R. D.; Trudel, S.; Berlinguette, C. P. J. Am. Chem. Soc. 2013, 135, 11580-11586.

(17) Xue, L.-X.; Meng, T.-T.; Yang, W.; Wang, K.-Z. J. Photochem. Photobiol., B 2015, 152, 95-105.

(18) Brimblecombe, R.; Dismukes, G. C.; Swiegers, G. F.; Spiccia, L. Dalton Trans. 2009, 9374-9384.

(19) Maeda, K.; Domen, K. J. Phys. Chem. C 2007, 111, 7851-7861.

(20) Bloomfield, A. J.; Sheehan, S. W.; Collom, S. L.; Anastas, P. T.

ACS Sustainable Chem. Eng. 2015, 3, 1234-1240.

(21) Liu, H.; Schilling, M.; Yulikov, M.; Luber, S.; Patzke, G. R. ACS Catal. 2015, 5, 4994-4999.

(22) Wang, J.; Li, K.; Zhong, H.-x.; Xu, D.; Wang, Z.-1.; Jiang, Z.; Wu, Z.-j.; Zhang, X.-b. Angew. Chem. 2015, 127, 10676-10680.

(23) Zhao, W.; Liu, Y.; Liu, J.; Chen, P.; Chen, I. W.; Huang, F.; Lin, J. J. Mater. Chem. A 2013, 1, 7942-7948.

(24) Masa, J.; Xia, W.; Sinev, I.; Zhao, A.; Sun, Z.; Grützke, S.; Weide, P.; Muhler, M.; Schuhmann, W. Angew. Chem., Int. Ed. 2014, 53, $8508-8512$.

(25) Wang, Y.; Ding, W.; Chen, S.; Nie, Y.; Xiong, K.; Wei, Z. Chem. Commun. 2014, 50, 15529-15532.

(26) Pfrommer, J.; Lublow, M.; Azarpira, A.; Göbel, C.; Lücke, M.; Steigert, A.; Pogrzeba, M.; Menezes, P. W.; Fischer, A.; SchedelNiedrig, T.; Driess, M. Angew. Chem., Int. Ed. 2014, 53, 5183-5187.

(27) Ressnig, D.; Shalom, M.; Patscheider, J.; More, R.; Evangelisti, F.; Antonietti, M.; Patzke, G. R. J. Mater. Chem. A 2015, 3, 50725082.

(28) Chen, Y.; Fu, L.; Liu, Z. Chem. Commun. 2015, 51, 1663716640 .

(29) Pintado, S.; Goberna-Ferrón, S.; Escudero-Adán, E. C.; GalánMascarós, J. R. J. Am. Chem. Soc. 2013, 135, 13270-13273.

(30) Goberna-Ferrón, S.; Hernández, W. Y.; Rodríguez-García, B.; Galán-Mascarós, J. R. ACS Catal. 2014, 4, 1637-1641.

(31) Galán-Mascarós, J. R. ChemElectroChem 2015, 2, 37-50.

(32) Yamada, Y.; Oyama, K.; Gates, R.; Fukuzumi, S. Angew. Chem., Int. Ed. 2015, 54, 5530-5530.

(33) Macartney, D. H. Rev. Inorg. Chem. 1988, 9, 101-151.

(34) Lee, G.-H.; Della Ciana, L.; Haim, A. J. Am. Chem. Soc. 1989, $111,2535-2541$.

(35) Brauer, G. Handbook of Preparative Inorganic Chemistry, 2nd ed.; Academic Press Inc.: New York, 1963; Vol. 1.

(36) Kenney, D. J.; Flynn, T. P.; Gallini, J. B. J. Inorg. Nucl. Chem. 1961, 20, 75-81.

(37) Liu, Y.; Wang, X. Polym. Chem. 2012, 3, 2632-2639.

(38) Jannuzzi, S. A. V.; Martins, B.; Felisberti, M. I.; Formiga, A. L. B. J. Phys. Chem. B 2012, 116, 14933-14942.

(39) Roy, X.; Hui, J. K. H.; Rabnawaz, M.; Liu, G.; MacLachlan, M. J. J. Am. Chem. Soc. 2011, 133, 8420-8423.

(40) Zhou, X.; Goh, S. H.; Lee, S. Y.; Tan, K. L. Polymer 1997, 38, $5333-5338$

(41) Valkama, S.; Hartikainen, J.; Torkkeli, M.; Serimaa, R.; Ruokolainen, J.; Rissanen, K.; ten Brinke, G.; Ikkala, O. Macromol. Symp. 2002, 186, 87-92.

(42) Sheng, K.; Yan, B. J. Mater. Sci.: Mater. Electron. 2010, 21, 6571.

(43) Ahn, H. S.; Tilley, T. D. Adv. Funct. Mater. 2013, 23, 227-233.

(44) Biesinger, M. C.; Payne, B. P.; Grosvenor, A. P.; Lau, L. W. M.; Gerson, A. R; Smart, R. S. C. Appl. Surf. Sci. 2011, 257, 2717-2730.

(45) Surendranath, Y.; Kanan, M. W.; Nocera, D. G. J. Am. Chem. Soc. 2010, 132, 16501-16509. 